\title{
Research and Application of Ontology in Resource Information Model of Tree Growth Management
}

\author{
Xuning Liu,Hongwei Song, Yuan Li,Jincui Kang \\ Department of Computer, \\ Shijiazhuang University \\ Shijiazhuang, China \\ E-mail:sjzhei@163.com
}

\begin{abstract}
In order to provide intellectual support for the construction of model resource of tree growth management, the paper carried out research on ontology and knowledge base technology, and the tree growth management resource information and ontology knowledge base were regarded as research target, which applied the ontology knowledge organization, then used semantic languages and resource model to study tree growth management resource knowledge base, discussed the acquisition, reasoning and other methods of tree growth management resource information. The practice has proved that resource information model of tree growth management based on ontology can acquire more parameters of tree growth management resource than traditional methods, which can provide sharing platform of resource information for tree growth management and contribute to construct the resource information model of tree growth management.
\end{abstract}

Keywords-ontology;tree;growth managemen; resource information

\section{INTRODUCTION}

The resource information of tree growth management is knowledge integration system that develops with the development and combination of artificial intelligence technology and resource information of tree growth management. Tree growth is not only process of system changing, but also is continuous process of information fusion, for example the environmental information of tree is confused with the structure information and physiological and ecological information. In order to perform intuitive research on variation that trees geometry and physiological and ecological characters develops with various environmental factors, we make the research on resources information of tree growth management[1].

By extracting the test observation data of tree growth over the years and based on the ontology the topological and organ morphological changes of tree are used to construct resource information base and knowledge base of tree growth management, and the unified sharing data platform is made to achieve the fusion of tree growth management resource information, provide the support for the simulation of tree growth process and reflect the regularity of tree growth, and it is a new method to explore intelligent of tree growth management model, so provide decision-making and theoretical basis for the tree growth management[2].

\section{TREE GROWTH MANAGEMENT RESOURCE INFORMATION}

\section{A. Information Collection}

The information that are related to tree growth management include mainly resource information and decision-making information of tree growth. The resource information of tree growth reflects the number of tree growth management resources, nature, location, environment, and can be divided into information of environmental resources and tree resources. The environmental resources information include site conditions, soil conditions, weather conditions, etc. The tree resources information include seedlings, tree species, tree growth conditions, stand structure; The management domain information of tree growth contains operating measures, decision-making elements of content knowledge, business decision-making information reflects the tree management resources business process, measures, modes, effects etc, which include tree management resources management measures such as the selection of seedlings, tending, fertilization, thinning, pruning, harvesting, etc, the data collection of time, process and work intensity of these management measures belong to operating decision-making information[3].

\section{B. Information Processing}

The original information can not reflect the trees growth mechanism due to the lack of the intrinsic relationship between the data rough or information[4]. So the need for processing of the raw data is made in order to lay the foundation for dynamic computer simulation of tree growth. The process mainly includes the following:

- Data mining methods are used to analyze the experimental observations data and make pretreatment, and the help is from quantitative treatment of tree growth, then extract feature information that reflects different growth stages of the trees such as plant topological structure and organ morphology.

- The genetic algorithms are used to select and make optimal combination of these feature information, remove minor and duplicate information, obtain the morphological parameters of physiological and ecological parameters at different growth stages of tree growth.

- According to different parameter types appropriate data structure is used to organize these information, 
and establish tree growth parameters base, so lay the foundation for the construction of growth models of tree.

- $\quad$ The fast-growing knowledge are difficult to obtain, and are not easy to be applied directly to the computer system. This paper uses data mining technology, after making the tree resources survey data, the fast-growing knowledge mining is made, and provides a new way of thinking for the fastgrowing knowledge acquisition, and performs quantitative analysis for the accuracy of knowledge, the decision-making becomes more scientific and accurate.

III. KNOWLEDGE BASE OF TREE GROWTH MANAGEMENT RESOURCE INFORMATION

\section{A. Resource Information Database of Tree growth management}

Resource database of tree growth management have certain disadvantages, the scale of most databases are small, and the data can not represent the situation of the field, information source type is not integrated, and the coverage is little. Data standardization and the degree of standardization in the field of tree growth management are bad, the data in tree growth management, many aspects of the formation such as construction, principle and representation of ontology and knowledge base have not formed a unified standard, the agricultural measurement unit and agricultural jargon synonym and homonym are serious in the information processing, which cause data dead ends, and even information garbage, some information are not accurate and complete, and the update is not timely, which do not timely response to the current situation, and the diversity of information resources are lack, multimedia information and fewer full-text information are little, and the degree of openness and sharing of information retrieval and navigation system are unreasonable and inefficient[4].

The database system is one kind of organized way and dynamic storage management, using a series of close ties data collection to establish tree growth management database and information systems[5], and its goal is to timely and accurate manage and use all kinds of useful trees growth of knowledge, information and high-tech achievements, greatly contributed to the promotion and application of scientific and technological achievements.

Resource information of tree growth management require the support of database, tree growth management database construction and improvement work includes further improvement and supplement of established tree growth management multimedia features of database and other manifestations of information, and the display of information includes maps, text, sound, multimedia; we should establish tree growth management standards synonymous with the image library with products associated database; and provide convenience multi-path and composite intelligent searching function[6].

\section{B. Resource Information Knowledge Ontology of Tree Growth Management}

Ontology provides the shared conceptualization specification for tree growth model, this specification is describe based on a kind of formal way, so that users and computers can share and reuse domain knowledge in a structured way. The ontology can clarify the structure of knowledge, the ontology elements such as concept, properties, functions, axioms and instances of domainspecific are used to describe knowledge and framework, ontology reuse can avoid repetitive domain knowledge, and unified terminology and concepts make knowledge sharing possible.

According to the definition of the ontology, the tree growth management resources information ontology are defined as the conceptual model which the tree growth management resource domain involves, and made consensus in tree growth management field of resource management, and can be expressed in computer and provides resource decision domain sharing of tree growth management. The tree growth management resource information ontology consists of the concept, properties, axioms, instances, the tree growth management resource decision-making concept refers to the collection of involved nouns in the process of tree growth management resources business, the areas are for tree growth management resource areas, including the collection of the tree growth management resources and operational decision making[7].

\section{Resource Information Knowledge Base of Tree Growth Management}

The ontology concepts is introduced in the knowledge base of tree growth management resources, which has important significance in knowledge organization and management, the ontology and knowledge base have the same characters in many ways, the ontology provides a more specific method of operation for the research and application of the knowledge base[7]. The ontology and knowledge base have the following in common: The ontology is a description of the objective world, and knowledge base is just the achievements of the objective world that people recognizes, both target are concepts/formalized of objective world or some domain ontology. It is the description of the objective world and must be the content that computer can recognize and express, the concept of knowledge in the knowledge base is also computer representation of the knowledge, both of which are based on computer expression as a general form and means, that is, the computer method ontology structure regards concepts, attributes, relationships, functions, axioms, instances as the main content, the knowledge base contains all of the ontology, making emphasis of requirements such as the concepts, relations, axioms, function, instance, both of the composition of the structure is basically the same.

The tree growth management resource decision-making knowledge base makes organizational knowledge ontology, and is conducive to knowledge management of knowledge. The ontology semantic structure based on logic language is integrity, and can ensure the integrity of the knowledge system in knowledge base, is the base of learning mechanism 
and the basis of the reasoning mechanism in knowledge base .The ontology has all kinds of editing tools, and provide a platform for knowledge representation and the achievement of knowledge base. The construction of ontology carries out the applications of the small-scale and complete contents, which can build open knowledge base and provide the application for production practices. The knowledge of tree growth management resource are acquired by the knowledge tree growth management resource decision-making process, The rules, theorems, laws, methods, data processing and database systems the general term of experience which can solve the problem of tree growth management resource management[7]. Structured information are the integration of actual tree growth management resource management theory, and practice and methods, which can answer the causes and mechanism of tree growth management resources business development, and can direct the tree growth management resource problems.

\section{CONSTRUCTION OF ONTOLOGY AND KNOWLEDGE BASE OF TREE GROWTH MANAGEMENT INFORMATION}

\section{A. The Construction of Ontology of Tree Growth Management Resource Information Model}

The project regarded tree growth management model as object, the construction of ontology database in tree growth management domain are the base of the system, this research intends to adopt the combination method of skeleton law that build corporate ontology and seven-step that build domain ontology to build domain ontology of tree growth management.

The subject uses RDF to describe meta-data model of tree growth management knowledge, and ontology editing tools PROTÉGÉ is used to create metadata RDF data documentation and Jena tool is used to achieve expression, parsing, query and simple reasoning of RDF data, so as to achieve the expression of trees growth management domains of the ontology; The concept of tree growth, property set, the set of instances, the axiom set four sets are considered to describe the knowledge model that has been established, and improving the accuracy of tree growth management knowledge representation and sharing. Analysis of the characters of the relationship between the growth of tree and areas of knowledge are made, the method is made by constructing the set of the tree growth management concept, attribute set, the set of instances, and trees community growth axiom set of tree growth knowledge model ontology, at last $0 \mathrm{wl}$ files are used to save ontology, then provide services for tree growth simulation knowledge.

\section{B. Construction of Knowledge Base of Tree Growth Management Resource Information Model}

In order to achieve the unified standardization, we have to achieve the name standardization of tree growth management resources, the problem will be resolved ontology library through the establishment of tree growth management domain ontology semantic dictionary; The help is from premise of reference national industrial and agricultural product classification standard (GB7653-87) and
Standard International Trade (SITC) we can study and formulate standards for classification of tree growth management parameters.

The ontology is used to build waterfall model, based on the existing knowledge ontology of agricultural science and technology literature, we can construct the tree growth management resource ontology and the decision-making ontology, and build standardized tree growth management resources knowledge conceptual system, so determine the various logical relationship between the concept and properties, which provides prerequisite for organizations of tree growth management as well as the growth of the resource information and knowledge model.

To build tree growth management database, the tree growth and development parameters are stored for the database, so that provide information on the growth and development model for the research of trees growth management; The tree growth management domain ontology knowledge base are built by research of knowledge base technology based on ontology, and develop the standardization and methods of tree growth management operating decisions, and the goal is to provide convenience for building and sharing within the industry, and provide favorable conditions and knowledge reasoning mechanisms for tree growth model database management system, so contribute to help users achieve intelligent decision support.

\section{IMPLEMENTTATION AND ANALYSIS}

\section{A. Construction of Growth Model of Tree}

The visual $\mathrm{C}++$ is regarded as development platform to build a visual model of tree growth based on tree growth management domain ontology database and visualization reference model and other infrastructure, combined with the Open Graphics Library (OpenGL) Kernel Library utility library functions, and the data are obtained by tree simulation model of effective organization and processing, then processed data are converted to graphical information through graphical algorithm, and tree growth model library of various developmental stages are built. The growth simulation of tree mainly performs qualitative observations of different growth conditions and different growth stages, then judge the growth mode, determine the overall framework of the morphology of its description, quantitative measure the tree topology, geometry, mechanical properties, extract the tree morphology rules model based on the growth rules, and simulate trees growth, and the establish tree growth model based on a variety of competitive factors.

\section{B. Implementation}

For the tree growth characters and the role of the external environmental factors, the system designs a basic properties dialog box, the dialog box can make interaction design, we can modify trees each organ attributes, such as blade type, the angle of the leaves and stems, branches way external environment variable are obtained by loading the data file. During the process of growth management process, the system provides users with the environmental parameters and tree growth parameters are regarded as input parameters 
of tree growth model, which simulate tree growth conditions, After physiological and ecological model calculations are made, the visualization model is available for the user.

\section{CONCLUSION}

The paper performed related research on ontology and knowledge base technology, and the ontology technologies are introduced into the field of information of tree growth management resources and explore the theory and technology of tree growth resource information modeling, the new concept such as tree growth management model resource information and tree growth model resource of the library were proposed. The ontology theory and database technology were combined to establish a domain ontology database and knowledge base of tree growth management, and the ontology theory was applied to the tree growth management knowledge in the field of management, then was specific application of ontology through the standardized naming, we established the field of tree growth management ontology knowledge base, which provided resource information and unified platform for the establishment of tree growth model.

\section{ACKNOWLEDGMENT}

We are very grateful to Professor Liu for his kind assistance and discussion. And we also thank for the support from China Agricultural University.

\section{REFERENCES}

[1]. W.D. Tang, C.X. Liu,P.P Liu,Z.P Lu.Study on the Digital Construction of Plant Growth Based on Information Fusion,Application Research of Computer,vol27,pp.34-36,2007.

[2]. B Song, X.L. Wang. Visualizing Landscape,Its Changes and Driving Processes. Nova Science Publishers,vol3.pp.167190,2006 .

[3]. Sheppard S R J, Meitner M. Using Multi-cfitofia Analysis and Visualization for Sustainable Forest Management Planning with Stakeholder Groups.Forest Ecology and Management,vol207,pp.171-187,2005.

[4]. Meitner M J, Sheppard S R J, Cavens D, eta1. The Multiple Roles of Environmental Data Visualization in Evaluating Alternative Forest Management Strategies.Computers and Electronics in Agriculture, vol49.pp.192-205,2005.

[5]. Song B,David J.Forest Visualization at Multiple Scales for Management and Planning.Series e. Technological Sciences,vol49,pp.27-34,2006.

[6]. Umeki K, Lim E M, A GIS-based Simulation Program to Predict Multi-species Size-structure Dynamics for Natural Forests in Hokkaido,Nohem Japan . Ecological Informatics, vol3,pp.218227,2008.

[7]. Chou C Y, Song B, Roy L H. Three-Dimensional Landscape Visualizations:New Technique Towards Wildfire and Forest Bark Beetle Management.Forests, vol2,pp.82-98,2010. 